\title{
大ロ径シリコンウェーハの高平坦両面研磨加工に関する研究* (加工条件の最適化)
}

\author{
廣 瀬 研 二*1, 榎 本 俊 之*2
Achievement of High Flatness of Large Diameter Silicon Wafer in Double-Sided Polishing (Optimization of Polishing Conditions Based on Kinematical Analysis)

\author{
Kenji HIROSE and Toshiyuki ENOMOTO*3 \\ ${ }^{* 3}$ Graduate School of Engineering, Osaka University, \\ 2-1 Yamada-oka, Suita-shi, Osaka, 565-0871 Japan
}

\begin{abstract}
Silicon ( $\mathrm{Si}$ ) wafers are the most commonly used substrates for the production of semiconductor devices. The design rule is miniaturization, and the chip size is increasing to improve the degree of the device integration. As the substrate, $\mathrm{Si}$ wafer is then required to be manufactured with higher flatness and larger diameter in order to meet the above demand. The double-sided polishing process is widely adopted as the finishing stage of the wafer manufacturing, because wafers with good surface quality and flatness can be obtained economically. However, the polishing technology has a serious problem: it is very difficult to set the appropriate conditions for stably polishing the Si wafer and wearing pad to high flatness in manufacturing. In this study, the optimization of double-sided polishing conditions was proposed and developed for overcoming the problem. As a basis, the model of the distribution of material removal on the wafer and the distribution of wear on the pad was developed based on kinematical analysis. The amounts of removal and wear are considered to be proportional to the sliding distance between wafer and pads. The optimization of the polishing conditions was performed utilizing a quasi-Newton method. As a result, the polishing conditions are clarified by minimizing the deviation of material removal distribution on the wafer and wear distribution on the pads, that is, achieving high flat wafer and pads.
\end{abstract}

Key Words : Polishing, Lapping, Accuracy, Tool Wear, Engineering Optimization, Flatness, Silicon Wafer, Double-Sided Polishing, Quasi-Newton Method

\section{1. 緒言}

半導体デバイスの高集積化にともなう微細化により, リソグラフィ工程においては基板材料となるシリコン ウェーハに対して極めて高い平坦度が要求されている. また製造コスト低滅を目的に，一枚のウェーハから取 得できるデバイスチップの個数を増やすためにウェー 八の大口径化が進んできた. そして現在は $\phi 300 \mathrm{~mm}$ ウェーハがおもに量産されているが， $\phi 450 \mathrm{~mm}$ ウェ 一八の検討(1)もすでに始まりつつある.

* 原稿受付 2008 年 4 月 11 日.

*1 大阪大学大学院工学研究科 (票565-0871 吹田市山田丘 2-1).

*2 正員, 大阪大学大学院工学研究科.

E-mail : enomoto@mech.eng.osaka-u.ac.jp
こうした次世代大口径ウェーハは $\phi 300 \mathrm{~mm}$ ウェー 八と同様の加工法，すなわち図 1 に示すような両面研 磨加工方式を基本とし, 加工装置のスケールアップ等 で対応することが考えられている，両面研磨加工法は キャリアによりウェーハを保持するため, 片面研磨加 エで生じるチャックによる平坦度劣化の恐れがなく, またウェーハより大きな研磿パッドを使用することで 加工進行にともなう研磨パッドの変化を抑制しやすく 安定した加工特性を得られるといった特徵を有する. これらの理由により $\phi 300 \mathrm{~mm}$ ウェーハは両面研磨加 エにより量産されている. しかし量産加工されている ものの, その安定性や経済性にはいまだ多くの問題が あり, さらに大口径化し平坦度仕様も高まる次世代ウ エーハ加工に現工法をそのまま適用することは極めて 困難である. 
そこでウェーハの高平坦研磨を実現するために，加 工条件の最適化に関する検討地がなされている。この 研究ではウェーハの自転までを考慮したウェーハ研 磨パッドの複雑な相対運動をモデル化しているが, ウ エー八面内の加工量の均一化のみを対象としている. しかし実際には研磨パッド内の摩耗量も均一にするこ とが極めて重要であり, 従来 工作物運動軌跡にもと づく解析(3)が数多く行われてきた. また加工現場にお いてはキャリアの回転方向を定期的に反転させパッド 上でのウェー八軌跡の偏りを減らしたり ${ }^{(4)}$ ，ドレッサ によりパッド形状を強制的に修正したりする作業が行 われている. しかしそれらの修正作業は作業者の経験 に強く依存し, さらに加工コストを大幅に高める要因 となっている. またスエードパッドのような軟質な研 磨パッドに対しては通常のドレスではパッド形状の制 御が極めて困難である.

そこで本研究では大口径シリコンウェー八を両面研 磨加工により高平坦に仕上げることを月的に加工条件 の最適化を行った．すなわち研磨パッドの偏摩耗を抑 制しながらウェー八を高平坦に仕上げられる加工条件 を幾何学的・運動学的理論解析にもとづき検討したの で報告する。

\section{2. 両面研磨加工のモデル化}

$2 \cdot 1$ モデル化の考え方 $\quad \phi 450 \mathrm{~mm}$ ウェー八の両 面研磨加工においては, 研磨装置のサイズなどを考慮 して1つのキャリア内には 1 枚のウェーハが収容され ると考えられる. そこで1バッチあたり 5 キャリア， 1 キャリアあたり 1 ウエー八の遊星歯車式両面研磨機 (キャリア径 約 23インチ) を対象としてモデル化す ることとした（図 2, 表 1). ウェーハは $\phi 300 \mathrm{~mm}$ と した.

ここで同図に示すように研磨パッド中心を原点とし た直交座標系 $\mathrm{xy}$, 同じく研磨パッド中心を原点とし た極座標系 $\mathrm{p} 0 \mathrm{p}$, ウェーハ中心を原点とした極座標系 $\mathrm{rw} \theta \mathrm{w}$ を設定し, 次節以降で述べるモデル化を行った. なお，xy および pop は静止系に固定された座標であ り， rwow はウェーハとともに回転する座標である. そしてウェーハおよひ研磨パッド内の各位置における 研磨量, 摩耗量はお互いの相対運動長さ, つまり摩擦 摺動距離に比例するとし, これを求めることで研磨量 および摩耗量分布の導出を行った.

$2 \cdot 2$ ウェーハ上のある位置における研磨パッドに 対するウェーハの相対速度 摩擦摺動距離を求める にあたり，まず $\mathrm{rw} \theta \mathrm{w}$ 座標系で表されたウェーハ上の ある位置（rwafl，Awafl）におけるパッドに対するウェ 一八の相対速度を求めた.

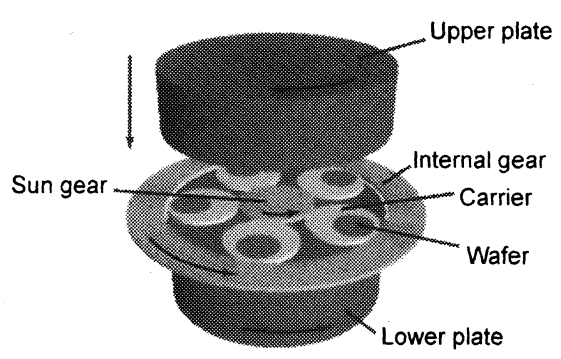

Fig. 1 Double-sided four-way polishing machine
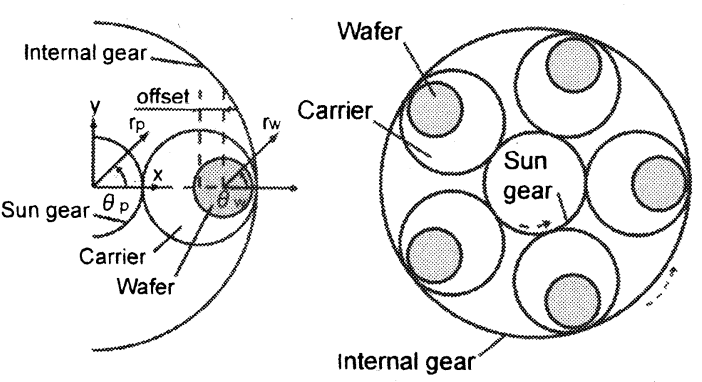

Fig. 2 Model of the double-sided polishing

Table 1 Polishing machine specifications

\begin{tabular}{l|r}
\hline Internal diameter of pad & $550.00 \mathrm{~mm}$ \\
External diameter of pad & $1635.00 \mathrm{~mm}$ \\
\hline Diameter of carrier & $584.91 \mathrm{~mm}$ \\
Diameter of sun gear & $507.59 \mathrm{~mm}$ \\
Diameter of internal gear & $1677.41 \mathrm{~mm}$ \\
\hline Distance between centers of & $120.60 \mathrm{~mm}$ \\
\hline carrier and wafer & \\
\hline
\end{tabular}

キャリアの自転および公転角速度を $\omega$ crot, w crev と し, 加工開始後 $t$ におけるウェーハ中心位置を $\mathrm{xy}$ 座 標で表したものを (xwafcl $(t)$, ywafcl $(t))$ とする.これ より maf1，Owaf1 を xy 座標系で表すと次式のように なる.ここで, $\omega$ waf はキャリアから見たウェーハの 自転角速度を表し，時間によらず一定であるとする。

$$
\begin{aligned}
& x_{\text {waf } 1}(t)=x_{\text {wafc } 1}(t)+r_{\text {waf } 1} \cdot \cos \left\{\left(\omega_{\text {crot }}+\omega_{\text {waf }}\right) \cdot t+\theta_{\text {waf } 1}\right\} \\
& y_{\text {waf } 1}(t)=y_{\text {wafc }}(t)+r_{\text {waf } 1} \cdot \sin \left\{\left(\omega_{\text {crot }}+\omega_{\text {waf }}\right) \cdot t+\theta_{\text {wa } 11}\right\}
\end{aligned}
$$

式(1)，(2)をそれぞれ時間微分することでウェーハ 上のある位置 (nwafl，Owafl）の xy 座標系におけるウ エ一八速度 vwafxl (t), vwafyl ( $($ )が求まる.

ここでウェーハの自転角速度 wwaf は次のように求 めた. ウェーハはパッドより受ける摩擦力によってキ ヤリア内で自転する．この摩擦力はパッドに対するウ エーハの相対速度に依存するものと考えられるため, ウェーハに働く回転モーメントの評価関数として $\mathrm{J} 0$ 
を設定する. ウェーハは中心回りの回転モーメントが 釣り合った状態で自転するはずなので，J0が 0 となる Wwaf が理論的なウェーハ自転角速度となる.ここで は，黄金分割法で J0 を最小にする $\omega$ waf 求め，ウエ 一八自転角速度とした.

次に, $x y$ 座標系で表したウェーハ上のある位置 xwafl, ywafl を $\mathrm{pp} \theta \mathrm{p}$ 座標系で表すと次式のようになる.

$$
\begin{aligned}
& r_{p a d 1}(t)=\sqrt{x_{\text {waf } 1}(t)^{2}+y_{\text {waf } 1}(t)^{2}} \\
& \theta_{\text {pad } 1}(t)=\tan ^{-1}\left(\frac{y_{\text {waf } 1}(t)}{x_{\text {waf } 1}(t)}\right)
\end{aligned}
$$

式(4)では，逆正接の中の分母が負の場合 $\theta p a d l(t)$ に $\pi$ を加える. 式(3), (4)より，位置 rpadl(t)，Opad1(t)での パッドの速度を $\mathrm{xy}$ 座標系で表すと次式のようになる。 ここで, wpadはパッドの角速度を表す.

$$
\begin{aligned}
& v_{p a d x 1}(t)=-r_{p a d 1}(t) \cdot \omega_{p a d} \cdot \sin \left(\theta_{p a d 1}(t)\right) \\
& v_{p a d y 1}(t)=r_{p a d 1}(t) \cdot \omega_{p a d} \cdot \cos \left(\theta_{p a d 1}(t)\right)
\end{aligned}
$$

vwafxl(t)，vwafyl(t)からそれぞれ式(5)，(6)を引いたも のがパッドに対するウェーハの相対速度の $\mathrm{xy}$ 成分 $\operatorname{vrelxl}(t), v \operatorname{vrlyl}(t)$ となる. これより, パッドに対するウ エーハの相対速度の絶対值および周方向成分は次式の ようになる.

$$
\begin{aligned}
& v_{\text {rel } 1}(t)=\sqrt{v_{\text {relx } 1}(t)^{2}+v_{\text {rely } 1}(t)^{2}} \\
& v_{\text {rele } 1}(t)=-v_{\text {relx } 1}(t) \cdot \sin \left\{\left(\omega_{\text {crot }}+\omega_{\text {waf }}\right) \cdot t+\theta_{\text {waf } 1}\right\} \\
& +v_{\text {rely } 1}(t) \cdot \cos \left\{\left(\omega_{\text {crot }}+\omega_{\text {waf }}\right) \cdot t+\theta_{\text {waf } 1}\right\}
\end{aligned}
$$

$2 \cdot 3$ 研磨パッド上のある位置におけるウェーハに 対するパッドの相対速度パッド中心を原点とし, パッドとともに回転する座標系 $\mathrm{p}^{\prime} \theta \mathrm{p}^{\prime}$ を定義し， $\mathrm{p}^{\prime} \mathrm{p}^{\mathrm{p}}$ ' 座標系で表されたパッド上のある位置（rpad2， Opad2')におけるウェーハに対するパッドの相対速度 を求める. 加工開始後 $t$ におけるウェ一八中心位置を xy座標系で表すと次式のようになる.

$$
\begin{aligned}
x_{\text {wafc } 2}(t) & =\frac{d_{\text {sum }}+d_{c a r}}{2} \cdot \cos \left(\omega_{\text {crev }} \cdot t+\frac{2 \pi}{5} \cdot n_{\text {car }}\right) \\
& +l_{o} \cdot \cos \left(\omega_{\text {crot }} \cdot t+\frac{2 \pi}{5} \cdot n_{c a r}\right) \\
y_{\text {wafa } 2}(t) & =\frac{d_{\text {sun }}+d_{\text {car }}}{2} \cdot \sin \left(\omega_{\text {crev }} \cdot t+\frac{2 \pi}{5} \cdot n_{\text {car }}\right) \\
& +l_{o} \cdot \sin \left(\omega_{\text {crot }} \cdot t+\frac{2 \pi}{5} \cdot n_{c a r}\right)
\end{aligned}
$$

ここで, ncarはキャリア番号であり 5つあるキャリ アをそれぞれ0〜4とする。

rpad2', Opad2' は rpop 座標系で次のように表される.

$$
\begin{aligned}
& r_{\text {pud } 2}=r_{\text {pad } 2} \\
& \theta_{\text {pud } 2}(t)=\theta_{\text {pad } 2}+\left(\omega_{p a d} \cdot t\right)(\bmod 2 \pi)
\end{aligned}
$$

rpad2，Opad2 はxy座標系で表すと次式のようになる.

$$
x_{\text {pad } 2}(t)=r_{\text {pad } 2} \cos \left(\theta_{\text {pad } 2}(t)\right)
$$

$$
y_{\text {pad } 2}(t)=r_{\text {pad } 2} \sin \left(\theta_{\text {pad } 2}(t)\right)
$$

式(13)，(14)をそれぞれ時間微分することでパッド上 のある位置 (rpad2', Opad2') の xy 座標系におけるパ ッド速度 vpadx2(t), vpady2(t)が求まる.

xpad2 (t), ypad2(t)は rw $0 \mathrm{w}$ 座標系では次式になる.

$$
\begin{aligned}
& r_{\text {waj } 2}(t) \\
& =\sqrt{\left(x_{\text {pad } 2}(t)-x_{\text {waf } 22}(t)\right)^{2}+\left(y_{\text {pad } 2}(t)-y_{\text {waf } 22}(t)\right)^{2}} \\
& \theta_{\text {waf } 2}(t)=\tan ^{-1}\left(\frac{y_{\text {pad } 2}(t)-y_{\text {wafc } 2}(t)}{x_{\text {pad } 2}(t)-x_{\text {waf } 2}(t)}\right)
\end{aligned}
$$

式(10)では逆正接の中の分母が負の場合 $\theta$ waf2(t)に $\pi$ を加える. ここで $\operatorname{waf2}(t)>150$ の時, パッド上のある 位置 (rpad2', Opad2') ではパッドはウェーハと接して いないので相対速度を 0 とする.

nwaf2 $(t)$, Owaf2(t)は xy 座標系では次式のようになる.

$$
\begin{aligned}
x_{\text {waf } 2}(t) & =x_{\text {waf } c 2}(t) \\
& +r_{\text {waf } 2}(t) \cdot \cos \left\{\left(\omega_{\text {crot }}+\omega_{\text {waf }}\right) \cdot t+\theta_{\text {waf } 2}(t)\right\} \\
y_{\text {waf } 2}(t) & =y_{\text {waf } 2}(t) \\
& +r_{\text {waf } 2}(t) \cdot \sin \left\{\left(\omega_{\text {crot }}+\omega_{\text {waf }}\right) \cdot t+\theta_{\text {waf } 2}(t)\right\}
\end{aligned}
$$

式(17)，(18)をそれぞれ時間微分することで，ウェ一 八上の位置（rvaf2 $(t) ， \quad$ ewaf2 $(t))$ の xy 座標系における ウェ一八速度 $v w a f x 2(t)$, vwafy2 $(t)$ が求まる。

vpadx2(t)，vpady2(t)からそれぞれ vwafx2(t)，vwafy2(t)を 引いたものがウェーハに対するパッドの相対速度の xy 成分 $\operatorname{vrelxz}(t), v \operatorname{rely2}(t)$ となる. これよりウェーハに 対するパッドの相対速度の絶対值は次式のようになる.

$$
v_{\text {rel } 2}(t)=\sqrt{v_{\text {rel }: 2}(t)^{2}+v_{\text {rely }: 2}(t)^{2}}
$$

$2 \cdot 4$ 摩擦摺動距離 ウェーハおよび研磨パッド 面内の研磨量や磨耗量はお互いの摩擦摺動距離に比例 すると考え, その摩擦摺動距離 $L$ および $L p$ を以下の 式より求めた. なお, 計算の際には表 2 の值を用いた. 


$$
\begin{aligned}
& L=\sum_{k=1}^{2}\left(\int_{0}^{T} v_{r e l 1, k}(t) d t\right) \\
& L_{p, k}=\int_{0}^{T} v_{r e l 2, k}(t) d t
\end{aligned}
$$

\section{3. 研磨加工条件の最適化}

$3 \cdot 1$ 最適化のための目的関数 ウェ一八および 研磨パッドを高平坦化する，すなわち摩擦摺動距離を 各面内で均一にすることが本報の月的である. そこで 式(20)をウェ一八全面にわたって計算し，その最大值 と最小值の差をウェーハに関する月的関数 Jw とする. 同様に, 式(21)よりパッドに関する月的関数を得る. なお上パッドに関する月的関数を Jpu，下パッドに関 する月的関数を $\mathrm{Jpl}$ とする.

次に, これらのウェーハおよび上下パッドの月的関 数に，それぞれ重み係数を掛けて足し合わせた多目的 関数 Jwp を定義する.Jwp を月的関数とした最適化 （最小化）を行うことでウェーハおよびパッド面内摩 擦距離分布を同時に均一化することができる.

$3 \cdot 2$ 加工条件の最適化 加工条件, すなわち設 計変数を太陽・内歯車, 上・下パッド回転数の 4 変数 とし，準二ュートン法を用いて最適化を行った. なお 実際の研磨加工装置の仕様を考慮し, 歯車と研磨パッ ドの最大・最小回転数をぺナルティ関数として設定し た. また, 研磨量を一定量に収めるためにウェ一八面 内の最大摩擦距離が初期值の $\pm 10 \%$, パッド面内の最 大摩擦距離が初期值の $\pm 20 \%$ に収まるようにやはりぺ ナルティ関数として考虑した.

ここで最適化計算を行う4変数の初期值としては, 加工現場で実際に用いられることの多い条件（表3中 Initial） (4)とした。これはウェ一八と各研磨パッド間の 摩摖距離全体がほぼ等しくなることを考え，設定され ており，各面内での分布についてはまったく考慮され ていない.

\section{4. 加工条件の最適化計算結果}

4・1 初期条件による面内摩擦距離分布表3に最 適化後の設計変数（歯車等の回転数）および初期值 • 最適化条件における月的関数（ウェ一八面内摩擦距離 最大差 $\mathrm{Jw}$, 上・下パッド面内摩擦距離最大差Jpu, Jpl）の值を示す．また，ウェーハおよびキャリアの 運動としてウェー八自転回転数 $\omega w a$ afとキャリアの自転 werot, 公転回転数 $\omega$ crevを示す. ここでウェ一ハのみ を月的関数として最適化した場合をOW，ウェ一ハ, 上パッド，下パッドを同時に最適化した場合をOwpと した. 各々の結果に対応するウェ一八面内摩擦距離分 布とパッド面内摩擦距離分布を図3，図4に示す.
Table 2 Parameters for calculating sliding distance

\begin{tabular}{l|c|l|c}
\hline \multicolumn{2}{|c|}{ L } & \multicolumn{2}{c}{ Lp } \\
\hline$\Delta$ rwaf & $10 \mathrm{~mm}$ & $\Delta$ rpad & $21.7 \mathrm{~mm}$ \\
$\Delta \theta w a f$ & $20^{\circ}$ & $\Delta \theta$ pad & $20^{\circ}$ \\
$\mathrm{T}$ & $60 \mathrm{~s}$ & $\mathrm{~T}$ & $60 \mathrm{~s}$ \\
\hline
\end{tabular}

\begin{tabular}{|c|c|c|c|}
\hline \multicolumn{4}{|c|}{ Design variables (Rotation of gears and pads) } \\
\hline & Initial & $\begin{array}{c}\text { Optimized } \\
\text { Ow }\end{array}$ & $\begin{array}{c}\text { Optimized } \\
\text { Owp }\end{array}$ \\
\hline$\omega$ sun rpm & 11.00 & 29.19 & 12.14 \\
\hline wint rpm & 10.00 & -10.96 & 6.75 \\
\hline 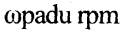 & -10.00 & -10.28 & -9.93 \\
\hline$\omega$ padl rpm & 30.00 & 30.34 & 31.89 \\
\hline
\end{tabular}

Table 3 Multi-objective optimization for polishing conditions

\begin{tabular}{|c|c|c|c|}
\hline & Initial & $\begin{array}{c}\text { Optimized } \\
\text { Ow }\end{array}$ & $\begin{array}{l}\text { Optimized } \\
\text { Owp }\end{array}$ \\
\hline JW mm & 64706 & 4765 & 7897 \\
\hline Jpu mm & 18244 & 11906 & 14900 \\
\hline $\mathrm{Jpl} \mathrm{mm}$ & 17752 & 36231 & 24565 \\
\hline \multicolumn{4}{|c|}{ Calclulated rotation of wafer and carrier } \\
\hline & Initial & $\begin{array}{c}\text { Optimized } \\
\text { Ow }\end{array}$ & $\begin{array}{c}\text { Optimized } \\
\text { Owp }\end{array}$ \\
\hline$\omega$ waf rpm & 0.43 & 38.63 & 6.73 \\
\hline$\omega c r o t$ rpm & 9.57 & -28.38 & 4.41 \\
\hline$\omega c r e v \mathrm{rpm}$ & 10.23 & -1.64 & 8.00 \\
\hline
\end{tabular}

(Max. difference in sliding distance on wafer and pads)

Ow : Optimized for only wafer

Owp : Optimized for wafer and pads

表3中の初期条件での月的関数および図3，図4より， 初期条件においてはウェ一八面内摩擦距離分布がテー パ状の傾きを示し, 摩擦距離最大差が大きくなってい る.この時, パッド中心に対するウェーハの回転であ るウェーハの相対自転回転数 $\omega w r e l$ は次式のように表 される.

$$
\omega_{\text {wrel }}=\omega_{\text {waf }}+\omega_{\text {crot }}-\omega_{\text {crev }}
$$

初期条件においてはwwrel-0.23 rpmであり，ほぼ0に 近い.このため, ウェーハが加工中にパッド中心に対 してほぼ回転せず, 摩擦距離分布がテーパ状になった と考えられる. 研磨パッドに関しては, 各パッド面内 での摩擦距離の差はあるものの上下で比較するとパッ ド面内摩擦距離が均等な分布となっている。これは3. 2節で述べたように，初期条件においてはキャリアの 公転回転数 $\omega$ crevとパッドの回転数との相対回転数が 上下でほぼ等しいためと考えられる.なお研磨パッド の半径方向中央付近で摩擦距離が増大しているが，こ れは害際の実験結果例(9)と対応するものである.

$4 \cdot 2$ ウェー八のみの平坦化を目的とした最適化 表3および図3，図4からわかるように，ウェ一八面内 摩擦距離分布が初期条件に比べて均一化されている （Ow）。最適化条件Owではwwrel 11.89 pmであり，ウ 
エーハがパッド中心に対してよく回転しているために 平坦化されたと考えられる，一方，研磨パッドに関し ては上パッドに対して下パッド面内の摩擦距離は3倍 以上となり（図4），また各面内での最大差も下パッ ドでは3倍程度大きくなってしまう（表3）。これはキ ヤリア公転回転数 w crevとパッド回転数との相対回転 数が下パッドでは上パッドの3倍以上となっているた めと考えられる.

このようにOWではウェーハのみの平坦化を 月的としているため, ウェー八面内摩擦距離 分布は均一化されているが, パッドに関して は最適化においてまったく考慮していないた めに上下パッドの不均等な摩擦距離や, 下パ ッド面内摩擦距離分布の偏りが発生している.

$4 \cdot 3$ ウェーハと上下パッドの同時平坦化を 目的とした最適化 ウェーハと上下パッド の同時平坦化を月的とした最適化の結果

（Owp），ウェ一八面内摩擦距離分布が初期 条件に比べて平坦化されている（表3，図3）。Owpで はwwrel 3.14 pmであり，Owによる結果ほどではない が，ウェーハがパッド中心に対してよく回転している ために平坦化されたと考えられる. 研磨パッドに関し ては, 初期条件に比べると多少上下パッドの面内摩擦 距離に差があるが, 上下パッドはほぼ同程度の摩擦距 離分布となっている．これはキャリアの公転回転数 wcrevとパッドの回転数との相対回転数が上下で近い 値のためと考えられる.

以上，Owpではウェー八と同時にパッドの平坦化も 月的としているため, ウェ一八面内摩擦距離分布を均 一にしつつ, 同時にパッド面内摩擦距離分布が面内も しくは上下で不均一になることを抑えることができた。

しかし図3, 図4からわかるように, 研磨パッド面内 摩擦距離分布においてはどの結果でもパッド半径方向 中間部で大きく, 中心および外縁に向かって小さくな っていく山型の分布となっている.これはパッド上の ウェー八軌跡からパッド中間部では縁に比べてウェー 八との接触時間が必然的に長くなるためであり, この 山型の偏摩耗分布は歯車およびパッド回転数を最適化 するだけでは抑制することができない，そこで次章に おいてキャリア内でのウェーハ位置に着月した平坦化 方法について検討することとした.

\section{5. 研磨パッド平坦化に関する検討}

$5 \cdot 1$ キャリア内ウェーハ偏心量の検討 キャリ ア中心からのウェーハの偏心量 (オフセット) を小さ くすることで, パッド面内摩擦距離分布の改善を図る. これはパッド半径方向のウェーハの移動量を小さくす
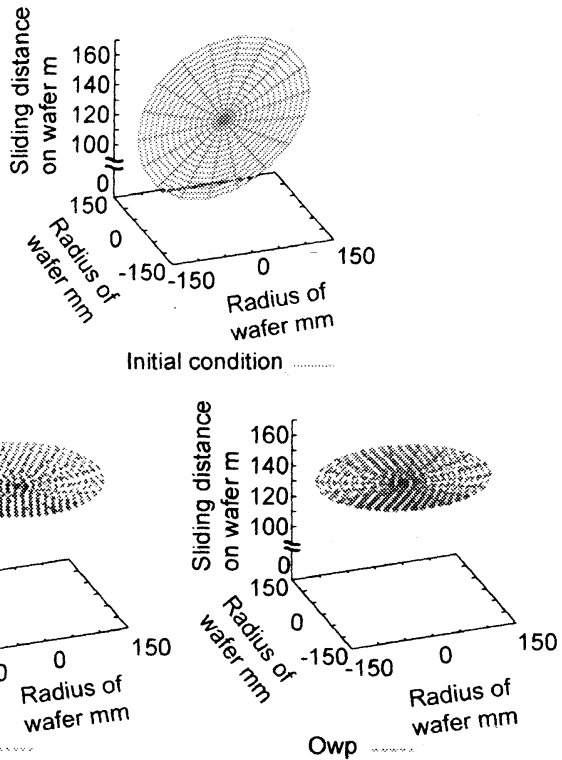

Fig. 3 Distribution of sliding distance on wafer

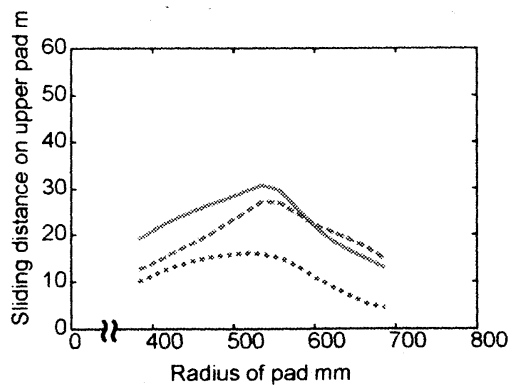

(a) Upper pad

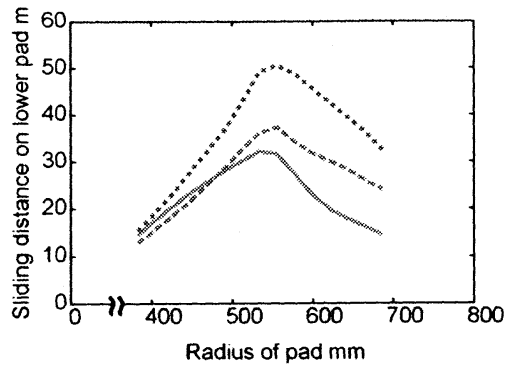

(b) Lower pad

Initial condition … Ow ..... Owp mmom

Fig. 4 Distribution of sliding distance on upper and lower pad

ることで, パッド半径方向中間部に集中した摩擦距離 の偏りを緩和することを月的としている.

4 章での最適化における初期条件之同様の条件でオ フセットを $0,60,120.6 \mathrm{~mm}$ と変化させた時のパッド 面内摩擦距離分布を図 5 に示す. オフセットを $60 \mathrm{~mm}$, $0 \mathrm{~mm}$ と小さくすることで摩擦距離分布の最大值付近 
で摩擦距離が増大し, 結果としてパッド中間部での摩 擦距離分布の傾きが緩やかになった，しかし，縁に向 かうにつれて傾きが急になり, また全体的に摩擦距離 が増大しパッドの消耗が早くなると考えられる.

$5 \cdot 2$ キャリア内ウェーハ偏心量および偏心方向の 検討 ウェー八偏心量だけでなくその方向も考慮す ることでパッド面内摩擦距離分布の改善を図る.まず 5 つのキャリア内のウェー八初期位置を交互に内（才 フセット -120.6）と外（オフセット 120.6）に配置し, 太陽・内蒾車を同期させて加工を行う。このとき研磨 パッド全体を均一に覆うようなウェーハ軌跡となる.

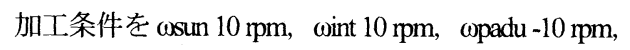
wpadl $30 \mathrm{pm}$ とした時 (altemation) と4 章での最適化初 期条件と同じ初期位置と加工条件（normal）でのパッ ド面内摩擦距離分布を図 6 に示す.パッド中間部で摩 擦距離が一部突出している部分はあるが, グラフの概 形をみると全体的に平坦な分布となっており，パッド 面内摩擦距離の山型分布を改善できることがわかった.

\section{6. 結言}

大口径シリコンウェー八を両面研磨加工により高平 坦に仕上げることを月的に, 理論解析にもとづき加工 条件の最適化を行った結果, 次のような結論を得た.

(1) ウェー八平坦化のみを考慮した最適化ではウェ 一八面内の研磨量分布は均一化されるが，上下の研磨 パッドの摩耗量が著しく異なってしまう。

(2) ウェーハおよび上下研磨パッドの平坦化を同時 に考慮し最適化することで, 研磨パッドの偏磨耗を抑 制しつつウェーハを平坦化できることがわかった.

(3) 研磨パッド面内の摩耗量分布の不均一は, キャ リア内でウェー八を適切な位置に設定することで改善 できる可能性があることがわかった.

本研究の遂行にあたり多大なご協力を賜りました浜 井産業株式会社に深く感謝の意を表します。

\section{文献}

(1) International Technology Roadmap for Semiconductors 2007 Edition, Executive Summary Final Draft, (2007Dec.), p.77.

(2) Nakagawa, Y., Optimization of Double Sided Polishing Conditions in order to Unify Friction Distance Distribution in a Wafer, Journal of the Japan Society for Precision Engineering, Vol.72, No.5 (2006), pp.641-646. (in Japanese)

(3) Uhlmann, E. and Ardelt, T., Influence of Kinematics on the Face Grinding Process on Lapping Machines, Annals of the CIRP, No.48, No.1 (1999), pp.281-284.

(4) Arai, H., Planarization Polishing Technique for Large Diameter of Bare Silicon Wafer, Journal of the Japan Society for Precision Engineering, Vol.73, No.7 (2007), pp.756-759. (in Japanese)

(5) Abe, K., Study for Lapping Technology of $400 \mathrm{~mm}$ diameter wafers -3rd report-, Proceedings of Spring
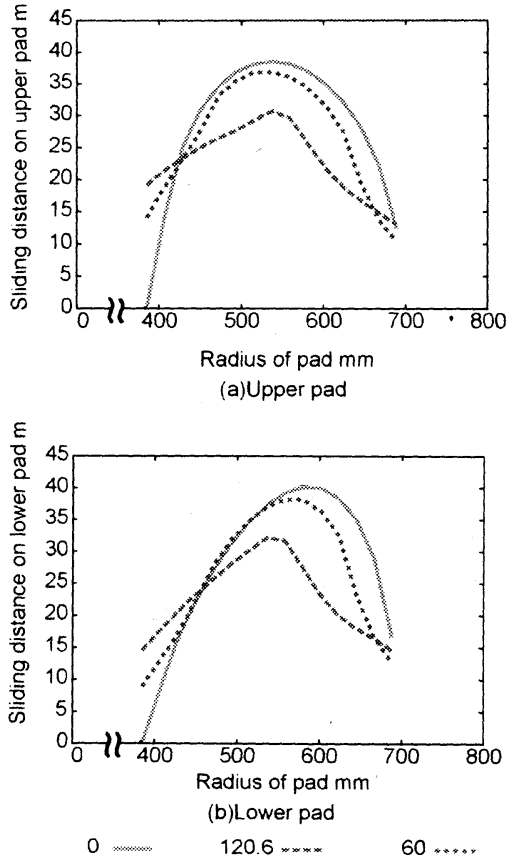

Fig. 5 Effect of offset distance on sliding distance
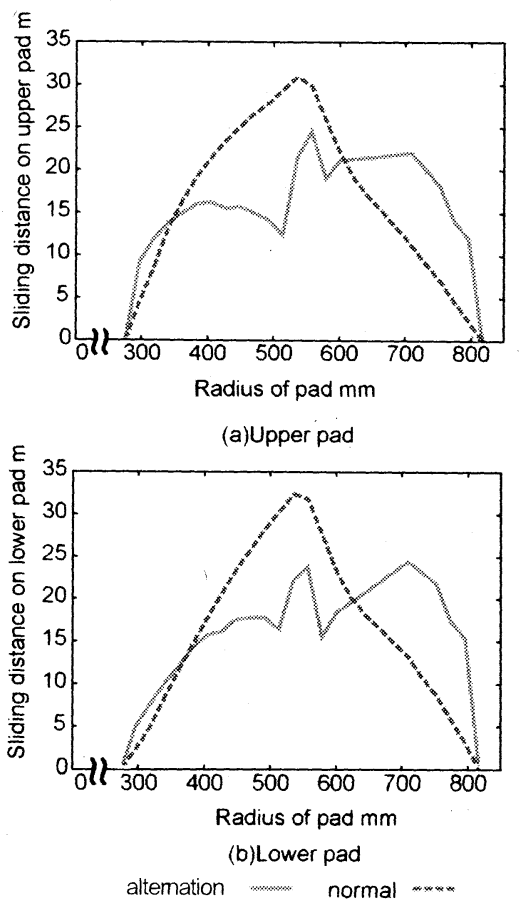

Fig. 6 Effect of offset distance and direction on sliding distance

Conference of the Japan Society for Precision Engineering, (1998), p.566. (in Japanese) 